\title{
Introduction to the special issue on the Econometrics of auctions
}

\author{
Pierre Dubois*, Marc Ivaldi ${ }^{\dagger}$ and Thierry Magnac ${ }^{\ddagger}$
}

November 27, 2009

This special issue on the Econometrics of Auctions is a follow up to the conference on the same topic organized in Toulouse in May $2006^{1}$ as a tribute to Jean-Jacques Laffont who passed away on May $1^{\text {st }}$ 2004. Jean-Jacques Laffont's contributions are important in many fields in economics, yet he still managed to spare some of his time to help to trigger the scientific quality uplift in the empirical analysis of auctions. Papers in this special issue continue this project and use Jean-Jacques' papers in the various dimensions of his work in theory, econometric identification, estimation and empirical results of auctions. This is why we wish to dedicate this special issue to the memory of Jean-Jacques Laffont and to his so formidable capacity of doing and inspiring excellent research in applied and theoretical economics.

In "Estimating Risk Aversion from Ascending and Sealed-bid Auctions", Jingfeng Lu and Isabelle Perrigne rely on multiple source of data to identify the risk aversion of bidders. Previous research using experimental or field data had proven the importance of risk aversion albeit in a parametric way. Risk aversion is difficult to identify non parametrically in the private-value paradigm if information consists only in observed bids (Athey and Haile, 2007). In particular, the influence of risk-aversion on observed bids of different organizational forms for the auction is

\footnotetext{
*Toulouse School of Economics (GREMAQ, INRA, IDEI)

$\dagger$ Toulouse School of Economics (GREMAQ, IDEI)

†Toulouse School of Economics (GREMAQ, IDEI)

${ }^{1}$ Conference web site is: http://idei.fr/activity.php?a $=4611$
} 
contrasted. In ascending auctions, it is a dominant strategy to announce each bidder's private value whatever risk aversion is. In first-price sealed-bid auctions, risk-aversion has a rôle to play considering the uncertainty attached to the bids of the other bidders. The comparison between data obtained under these two designs should allow for the identification of risk aversion. What Jingfeng and Isabelle do is to provide a constructive proof of non parametric identification of bidders' risk aversion and an estimation procedure that builds on it. Obviously, one needs to assume that the distribution of private values remain the same across different auction designs. Jingfeng $\mathrm{Lu}$ and Isabelle Perrigne show that it seems a reasonable assumption in the data they use that are drawn from timber auctions organized by the US Forest Service. They estimate risk aversion non parametrically and show that although imperfect, a Constant Relative Risk Aversion assumption leads to a better fit than a CARA specification.

In "Multi-Round Procurement Auctions with Secret Reserve Prices: Theory and Evidence", $\mathrm{Lu} \mathrm{Ji}$ and Tong Li tackle the estimation of a multi-round auction which is a complex game. Some advances in the estimation of these games had been proposed by Elyakime, Laffont, Loisel and Vuong (1997). What the authors focus on is that the auctioneer can auction again later the objects that were not sold in the first auction. This can happen because of the use of a reserve price that, in the present case, is secret. Lu Ji and Tong Li first construct a theoretical model where bidders draw at each period but in a time-independent distribution, their private value for the object. A secret reserve price is set by the auctioneer according to some evaluation of the private value for the seller. The only thing that changes between rounds is thus the beliefs of the bidders on the support of the reserve price. Lu Ji and Tong Li first show that equilibrium bids decline over rounds. Second, they estimate their model using data on auctions from the Indiana Department of Transport. Because of the small number of bids, they use parametric specifications and estimate the parameters using simulated maximum likelihood estimation methods. They are, as a consequence, able to simulate counterfactuals that show the importance for the seller of using a secret reserve price and setting it up at the right level.

In "Econometrics of Auctions by Least Squares", Leonardo Rezende proposes a simple way to recover the estimates of the coefficients of the determinants of the mean and variance of the distribution of private values in an auction. What he proposes is a particular case of the method 
of moments developed by Laffont, Ossard and Vuong (1995). Leonardo restricts his attention to symmetric independent private values where the distribution of private values is assumed to belong to some specific families of distributions. Leonardo Rezende shows that in this case, simple OLS leads to consistent estimates of the coefficients of the determinants of the mean and variance of the private value distribution of the auction. This provides an interesting and easy first step for estimating these coefficients. It can also give some information about the shape of the distribution of private values. This procedure is illustrated using data on EBay auctions.

In "Approximation of Nash Equilibria in Bayesian Games", Olivier Armantier, Jean-Pierre Florens and Jean-François Richard propose simple solutions to complex games. They propose to look for Nash equilibria in games where the strategy space has been restricted. This is a method which is akin to discretization or restrictions on policy functions in complex decision problems (Judd, 1999). The authors show that some sequence of Nash equilibria of the restricted games converges to a Nash equilibrium of the complete game. Furthermore, they develop measures of the quality of approximation that restricting the set of strategies bring about. They show the interest of their approach in the case of private-value auction examples. They are careful in proceeding step-by-step. Their first example is a simple private-value auction and allows for a direct computation of the Nash equilibria and for the evaluation of the quality of the approximation method they propose. In the second example, although more complex since the auction is now asymmetric, there is another existing approximation method to which the Constrained Strategic Equilibrium can be compared to. Finally, their last example is a demonstration of the simplicity of their approach since no other method is known in that case.

In "Non parametric identification and estimation of a class of common value auction models", Philippe Février turns away from the private value paradigm and studies identification in the pure common value model. Identification of structural parameters in this model is difficult and cannot be obtained without additional identifying restrictions (Laffont and Vuong, 1996). Such a set of additional identifying restrictions was proposed by Li, Perrigne and Vuong (2000). Philippe Février proposes another set of additional identifying restrictions. Philippe shows that it is sufficient that the model be written as depending on three functions only: the density function of the true value and two functions that define the conditional distribution of the signal, conditional on the true 
value. These two functions respectively define the conditional density function and the support of the density function of the signal conditional on the true value. What Philippe Février shows is that these three functions are identified from the distribution of observed bids. The interest of this approach lies in the fact that it is possible to set up a direct estimation method from the observed bids instead of relying on two-step methods. Philippe Février exhibits relatively mild conditions under which the estimator that he proposes is uniformly consistent. Further research would be needed to derive the asymptotic distribution of the estimates.

As a last word, we would like to acknowledge funding of the conference by Agence France Trésor, Institut d'Economie Industrielle, INRA, Région Midi-Pyrénées, CEPR and the Journal of Applied Econometrics and we would like to thank all the staff of IDEI that were involved in the organization and especially Christelle Fauchié and Florence Chauvet. 


\section{References}

Athey, S. and P., Haile, 2007, "Non Parametric Approaches to Auction", in J.J. Heckman and E. Leamer eds, Handbook of Econometrics, Volume VI, Amsterdam North Holland.

Elyakime, B., J.J., Laffont, P., Loisel and Q., Vuong, 1997, "Auctioning and Bargaining: An Econometric Study of Timber Auctions With Secret Reservation Prices", Annales d'Economie et de Statistiques, 34:115-141.

Judd, K., 1999, Numerical Methods in Economics, Cambridge: MIT Press.

Laffont, J.J., H., Ossard and Q., Vuong, 1995, "Econometrics of first-price auctions", Econometrica, 63:953-980.

Laffont, J.J. and Q., Vuong, 1996, "Structural Analysis of Auction Data", American Economic Review, Proceedings, 36:414-420.

Li, T., I. Perrigne and Q., Vuong, 2000, "Conditionally Independent Private Information in OCS Wildcat Auctions", Journal of Econometrics, 98:129-161.

Paarsch H.J., and H. Hong, 2006, An introduction to the structural econometrics of auction data, Cambridge: MIT Press. 


\section{Table of Contents}

1. Jingfeng Lu and Isabelle Perrigne, "Estimating Risk Aversion from Ascending and Sealed-bid Auctions"

2. Lu Ji and Tong Li, "Multi-Round Procurement Auctions with Secret Reserve Prices: Theory and Evidence"

3. Leonardo Rezende, "Econometrics of Auctions by Least Squares"

4. Olivier Armantier, Jean-Pierre Florens, Jean-François Richard, "Approximation of Nash Equilibria in Bayesian Games"

5. Philippe Février, "Non parametric identification and estimation of a class of common value auction models" 